strengthens the suggestion that $\mathrm{EB}$ virus may be the causative agent of Burkitt's lymphoma.

Watson, Ralph, Sarkar and Cohn (Proc. US Nat. Acad. Sci., 66, 344; 1970) have reported experiments which raise the possibility that a leukaemia type virus is involved in the aetiology of mouse myeloma. They have found a positive correlation between the capacity of mouse myeloma cells in culture to synthesize immunoglobulins and to produce a murine leukaemia type virus. Using various tests, Watson et al. identified the virus-like particles seen in the myelomas and in their culture media as a virus closely related but not identical to known murine leukaemia viruses. The myeloma cells which produce virus carry the Gross leukaemia type $G$ antigen and the viruses themselves have leukaemia group specific antigens. Moreover, Watson et al. have found that a variant line of myeloma cells, isolated by Schubert and Cohn in 1968, which fails to synthesize immunoglobulins also fails to produce virus. And some variant cells selected for lack of leukaemia antigens also failed to synthesize detectable amounts of immunoglobulin proteins.

\section{DISEASE TRANSMISSION}

\section{Viruses on the Wind}

\section{from our Microbiology Correspondent}

During the past few years, evidence has been accumulating to implicate climatic conditions as a major factor in the dissemination of foot and mouth disease. Last year (Nature, 223, 712; 1969), Smith and Hugh-Jones reported that wind could be of primary importance, and now, two years after the last calamitous outbreaks in England and Wales, Hugh-Jones and Wright have published a study of the 1967-8 epidemic in relation to the then prevailing weather ( $J$. Hygiene, 68, 253; 1970). Although numerous agencies have been suggested as carriers of the virus-animals, carcasses, milk, bones, birds, rats, hay, vehicles and humans included-the eause of only 5 per cent of the outbreaks in 1967-8 was established conclusively. How then did most of the infections-more than 2,000-occur? Hugh-Jones and Wright's analyses show that wind and subsequent precipitation were strong contenders for the role of chief disseminating agents.

The first identified outbreak was on a farm at Nant Mawr, Shropshire, in October 1967. The pattern of the spread of the disease from this centre conformed to that predictable for windborne spread from a point source. The mean bearing of outbreaks in the invasion sector was $039^{\circ}$, while the concurrent mean surface and 2,000 foot wind directions were $034^{\circ}$ and $068^{\circ}$ respectively. Moreover, a calculation of the axis of a plume of windborne material in these conditions gave a value of $041^{\circ}$. Thus, the initial spread in the epidemic of 1967-8 was aerial and relatively close to the ground.

An investigation of a sub-epidemic near Worcester proved particularly interesting because of its isolated situation. Foot and mouth disease was introduced into this area in skim milk pig feed, but subsequent spread in the locality was by other means. Indeed, the subscquent pattern of outbreaks accorded closely with the weather conditions. Thus, there was little if any spread during a subsequent dry, anticyclonic period with little wind, although there were adequate numbers of susceptible stock on nearby farms. With the return of rain, however, there were fresh incidences of the disease. As well as transmission of the virus for short distances by wind, cases of windborne infection for 60 to $110 \mathrm{~km}$ were detected. The data collected from the 1967-8 epidemic also point to an association between wind speed and rate of spread of the dicease. In midNovember, for example, a sharp decrease in the rate of spread coincided with the onset of dry weather, whereas maximal rates of spread later in the winter correlated with periods of snow bearing winds.

If foot and mouth disease is transmitted by wind, several assumptions relating to the release of the virus into the air, its transportation and eventual deposition must be made. The virus can be emitted from infected animals in several ways, including sneezing, and probably appears in droplet nuclei in the air. The size of the droplets largely determines the extent of spread; strong winds which dehydrate and fragment large droplets lead to greater spread. One case history investigated in detail by Hugh-Jones and Wright argues forcibly for an aerosol transmission of foot and mouth disease. In concluding that wind is responsible for spread they are rather pessimistic about the chances of finding an effective means of containing the disease. Accurate weather forecasting coupled with early diagnosis should aid farmers and epidemiologists and enable them to alert and concentrate on areas of probable infection. Immediate slaughter of all infected and contact animals remains the chief method of choice for containing the disease in Britain.

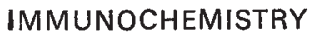 \\ Eye on Antibodies}

\section{from a Correspondent}

ImMunochemists from ten laboratories cross matched almost seventy antibodies to the proteins of the vertebrate eye lens when an international working party on crystallin immunochemistry met in the MRC Epigenetics Research Group, Edinburgh University, from June 23 to July 6 . Additional antibodies are expected from three more laboratories. The lens of the vertebrate eye is often used to study problems of embryonic induction, tissue specificity and metaplasia, regulation of protein synthesis and protein evolution. Lens proteins, or crystallins as they are called, are also studied in cataract and other human pathological conditions. Because the crystallins are non-enzymatic, immunochemical procedures are used in their recognition. If antibodies of unknown differences in specificity are used discrepancies in the literature are to be expected, yet it has become increasingly necessary to be able to make detailed rather than very general correlations between data from various laboratories. To achieve this, the antibodies were cross matchcd both qualitatively and quantitatively in standard conditions against a panel of antigens.

The test panel included antibodies to total crystallins of fifteen species including man, bovine, chick and amphibia and antibodies to restricted fractions from several of these species. The pancl of test antigens included total crystallins of fourteen species to fourteen different preparations of human, bovine, and chick crystallins fractionated by chromatography or isoelectric focusing and ten highly purified bovine crystallin fractions, including crystallin subunits. 